\title{
INVESTIGATION OF THE RELIABILITY OF LOCAL STRAIN ANALYSIS BY MEANS OF THE TRIANGLE MODELLING
}

\author{
Janusz BOGUSZ ${ }^{1)}$ *, Anna KLOS ${ }^{1)}$, Mariusz FIGURSKI ${ }^{1)}$, \\ Marek JAROSINSKI ${ }^{2)}$ and Bernard KONTNY ${ }^{3)}$ \\ 1) Centre of Applied Geomatics, Military University of Technology, Warsaw, Poland, \\ 2) Polish Geological Institute, Warsaw, Poland \\ 3) Institute of Geodesy and Geoinformatics, Wroclaw University of Environmental and Life Sciences, Poland \\ *Corresponding author's e-mail: jbogusz@wat.edu.pl
}

(Received February 2013, accepted May 2013)

\begin{abstract}
The GRID_STRAIN software that runs under the MATLAB ${ }^{\circledR}$ environment helped us in achieving the continuous strain field model. Unfortunately, the program averages the results. Therefore, the authors' main goal of this paper was to work out a method of good verification of data to avoid falsifying of the results of strain calculations. We decided to use the method of the Delaunay triangulation to build a set of triangles of the data (EPN and ASG-EUPOS stations as the vertexes) and by the use of the velocities of each point and their errors, to estimate the single strain in each triangle. This approach made it possible to exclude the outlying values from the data. Selection of the criteria of the characteristic of insufficiently stable points in order to remove them from further computations is of a great importance for the final results of computations of the deformation field. In such a tectonically stable region, as the area of Poland, the strain values should not be higher than 3 to 4 nanostrains/year. At the low rate of tectonic deformations observed in Poland, the disturbances resulting from insufficient stabilization of the ASG-EUPOS network influence the computations of the deformation field to a significant extent. Improper stabilization of a single permanent station causes unification of the deformation field within 2 to 3 computation triangles having a common vertex at this station. Based on this assumption, nearly 30 of the ASG-EUPOS stations were excluded from further strain calculations. The analysis of the geodynamic consistency of the deformation field for the computation triangles is basis for indicating stations for which the dislocation resulting from insufficient stabilization, significantly exceeds the dislocation resulting from the deformation of the lithosphere. Most of the ASG-EUPOS network stations may be used for analysis of local differentiation of the deformation field in Poland. The regularities of the deformations distribution determined by ASG-EUPOS network stations constitute a new set of data which will be used for further geodynamic interpretation. In case of lower rank disturbances resulting from destabilization of the network stations, this factor's component cannot be recognized using qualitative analysis of the deformation field.
\end{abstract}

\section{KEYWORDS: Delaunay triangulation, strain field, EPN, ASG-EUPOS, GPS, GRID_STRAIN}

\section{INTRODUCTION}

The verification of stations that record permanently the satellite observations seems to become more and more significant issue nowadays. Many artificial changes in the GPS time series occur which are mostly related to the seasonal errors from satellite orbital models, atmospheric models, water vapour distribution models, phase centre variation (PCV) models, thermal noise of antenna, local multipath and snow cover of the antenna (Dong et al., 2002). Seasonal variations of the ionosphere may also introduce artificial signals (Shagimuratov et al., 2002). It was shown in the paper by Bogusz and Figurski (2012) that the same short-period effects exist in the GPS data gathered by the EUREF Permanent Network (EPN) and the Polish GroundBased Augmentation System (ASG-EUPOS) stations and could efficiently be transferred into long-period oscillations in the daily solutions. In the paper by Kontny and Bogusz (2012), authors made the comparative analysis of the vertical movements determined with GPS permanent stations and the data from the first and second class geometric state levelling network. They obtained a lot of differences in the analyzed models.

Geodynamical interpretation of such data could be extremely distorted and could lead to wrong conclusions. A few verifications of the data reliability based on GPS time series were previously made by Borkowski et al. (2003) or Schenk et al. (2010). After verification of the data it is more likely to obtain real changes that appear between various or at the same geological structure. In this research we considered both: the regional velocity field (for the whole area of Poland) as well as the local one for the Sudeten region.

A lot of models proving the existence of the geodynamical movements in the area of Poland, Sudeten and the Bohemian Massif were previously made. Schenk et al. (2000) proved the existence of annual movements at the level of a few millimetres for the area of Sudeten. Schenk et al. (2009) showed the trends of local movement for West Bohemia what confirmed the extension in the WSW-ENE direction. 
Schenkova et al. (2007) obtained sinistral movements at the level of 1-2 $\mathrm{mm} /$ year by the network of GPS sites from the area of the Bohemian Massif. Schenkova et al. (2009) analyzed the crustal movements for the Bohemian Massif. Their results were in a good agreement with the previous ones they obtained the same rate of sinistral movements and indicated two zones with extension trends. Bogusz et al. (2013) created the continuous velocity field based on the ASG-EUPOS network and proved the existence of possible displacements among data points at the level of several millimetres. Jarosinski et al. (2009) discussed the cenozoic dynamic evolution of the Polish Platform, the directions of dominating stresses were also taken into consideration. They made a conceptual model and attempted to elucidate the dynamic changes of the intraplate deformations. Gruenthal and Stromeyer (1992) analysed the main SHmax directions from the area of Europe and indicated the directions of regional stress pattern based on the finite element modelling. They showed that the well-known NW-SE stress directions in the Western part of Europe change to NE-SW and even to E-W ones in the Eastern part.

Determination of the strain rates or strains in triangles may be a very efficient tool of data verification. The strain values are determined by velocities from three sites and abnormal strain values or directions could indicate deficiencies in the reliability. These deficiencies could result for instance from the antenna mounting. Presently most of GPS antennas are placed at the buildings and changes of coordinates may indicate for instance their subsidence. On the other hand, the movement of antennas placed at a pillar has to be interpreted in a wider geological context since it could reveal displacements of small structures.

Such analyses were previously presented in the papers by Lukhnev et al. (2010), who used the BaikalMongolian GPS triangulation network to compute strains in the triangles and England and Molnar (1997; 2005), who derived the strain rates within triangular regions in Asia from Quaternary slip rates.

\section{DATA}

The ASG-EUPOS network consists of over 130 stations that are placed on area of Poland and the neighbouring countries as well. It was established in 2008 by the Head Office of Geodesy and Cartography and it constitutes a multifunctional system of GPS stations which task is the precise positioning of points. Data collected at the ASG-EUPOS stations are available for the Centre of Applied Geomatics that operates at the Military University of Technology (MUT), Warsaw as one of 18 independent EPN Local Analysis Centres (LAC) in Europe. EPN is a sciencedriven network of continuously operating GPS reference stations with precisely known coordinates in the ETRS89 (European Terrestrial Reference System) (http://www.epncb.oma.be/). The latest processing of
GPS data from EPN and ASG-EUPOS stations made in MUT LAC covered 209 GPS weeks (from 1466 to 1675). Data used in this research included more than 300 stations (the sum of ASG-EUPOS and EPN stations). Figure 1 presents the stations situated on the area of Poland and the neighbouring countries.

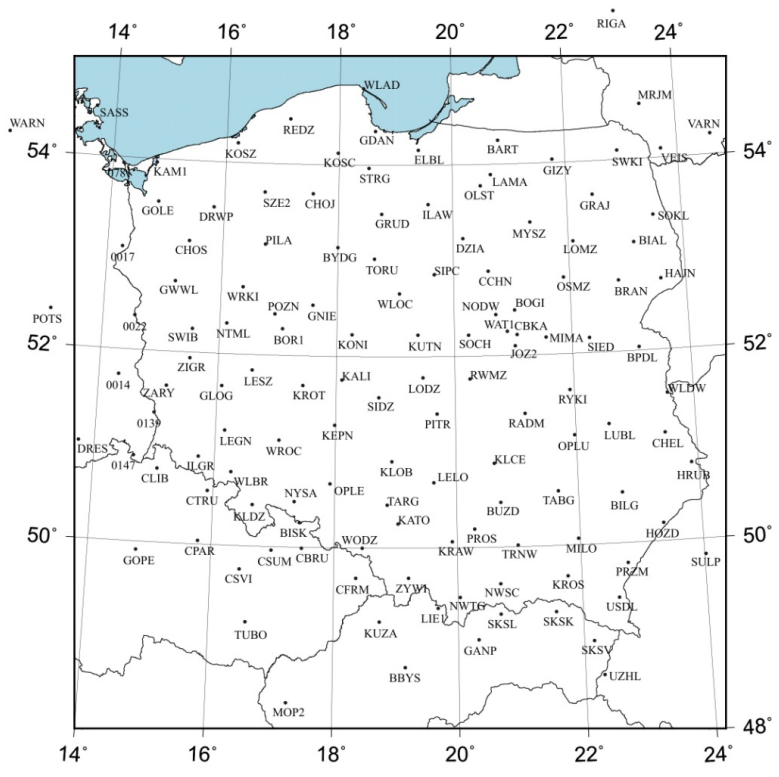

Fig. 1 Permanent GPS stations considered in the research.

The absolute velocities in the ITRF2008 (International Terrestrial Reference Frame; Altamimi et al., 2011) reference frame were estimated with CATREF software (Altamimi et al., 2007). Several determinations of the velocity field on the basis on the ASG-EUPOS stations were previously made. The factors that could diminish the statistical reliability of the velocities determined from time series of geocentric coordinates were described previously by Figurski et al. (2010). They showed many non-linear changes caused by snow coverage or hydrological influence appearing as an annual curve.

The absolute velocities were then reduced by various plate motion models available on UNAVCO Plate Motion Calculator (www.unavco.org) to obtain the intra-plate ones, additionally the velocities in the ETRF2000 reference frame were calculated (Boucher and Altamimi, 2011). The comparison of intra-plate velocity components at each station was done. Unacceptable discrepancies between the particular models were discovered. Figure 2 presents the intraplate velocities components of WROC (Wrocław, Poland) and KATO (Katowice, Poland) stations (blue colour corresponds to the northern component, red colour to the eastern one).

What is surprising, the differences between the models reach sometimes even $3 \mathrm{~mm} /$ year for the same component (for example APKIM2005-IGN model and 

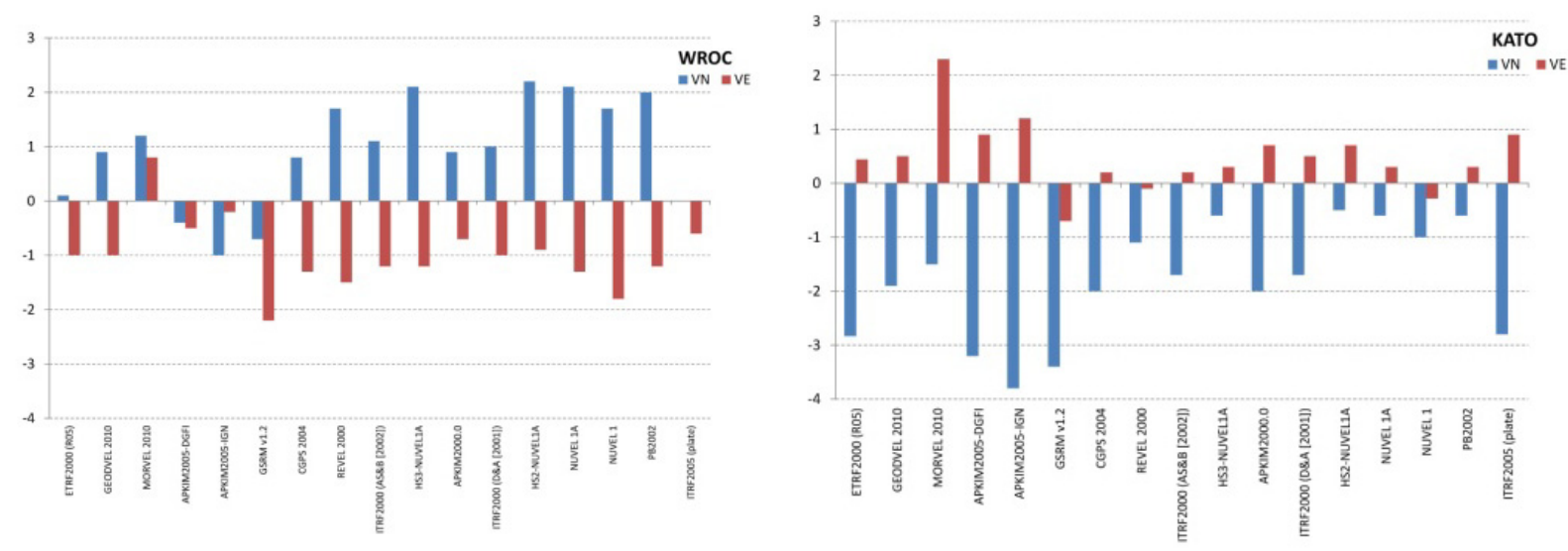

Fig. 2 Velocities components [mm/year] of WROC and KATO stations reduced with the various plate motion models.

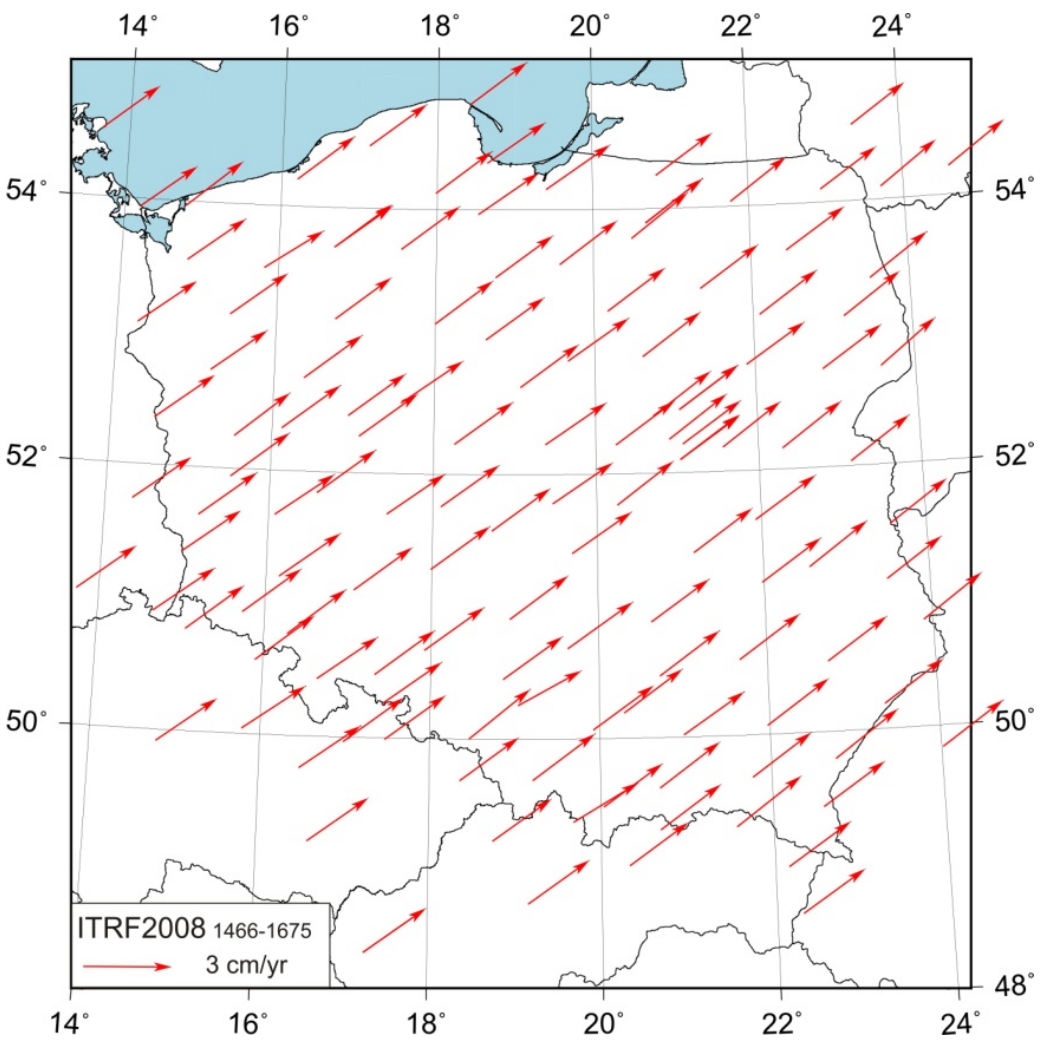

Fig. 3 Velocities for the ASG-EUPOS stations (ITRF2008, GPS week 1466-1675).

REVEL 2000 for KATO station). They show that the intra-plate velocities are not reliable, nowadays we are not able to provide $100 \%$ trustworthy model of the Eurasian plate movement. Therefore, the authors decided to use the absolute velocities in the ITRF2008 reference frame to model the strains for the area of Central Europe. The horizontal velocity field in the area of Poland from the newest MUT LAC solution is presented in Figure 3.
The continuous strain field based on previously determined velocities and their uncertainties was calculated with the GRID_STRAIN software (Teza et al., 2008) that runs under MATLAB $\mathbb{}$ environment (Military University of Technology, license No. \#350334). It estimates the strains (by means of the values of compression and tension with their directions) and plots them with the great amount of figures that are helpful in describing the results. It 
calculates the strain field using the modified least squares method (Shen et al., 1996):

$$
\begin{aligned}
\left(\begin{array}{c}
V_{x}^{I} \\
V_{y}^{I}
\end{array}\right) & =\left(\begin{array}{cccccc}
1 & 0 & \Delta x_{I} & \Delta y_{I} & 0 & \Delta y_{I} \\
0 & 1 & 0 & \Delta x_{I} & \Delta y_{I} & -\Delta x_{I}
\end{array}\right)\left(\begin{array}{c}
U_{x} \\
U_{y} \\
\tau_{x x} \\
\tau_{x y} \\
\tau_{y y} \\
\omega
\end{array}\right)+ \\
& +\left(\begin{array}{c}
\sigma V_{x}^{I} \\
\sigma V_{y}^{I}
\end{array}\right)
\end{aligned}
$$

where $V_{x}^{I}$ and $V_{y}^{I}$ are the velocity components of the $I$ th station with the vector of position $\vec{r}_{I}$. With the use of Eq. (1) six parameters can be estimated. These are: $U_{x}, U_{y}$ - the components of translation velocity vector, $\omega$ - the velocity of rotation of the network rigid area and $\tau_{x x}, \tau_{y y}, \tau_{x y}$ - the main strain components. $\varepsilon_{x}^{I}$ and $\varepsilon_{y}^{I}$ are the uncertainties of the velocities components: $V_{x}^{I}$ and $V_{y}^{I}$, respectively. All of the variables on the right side of Eq. (1) are estimated for the node with the vector of position equal to $\vec{R}$. Consequently, $\Delta x_{I}$ and $\Delta y_{I}$ are the components of the vector: $\Delta \vec{R}_{I}=\vec{r}_{I}-\vec{R}$

The results of strains estimated in GRID_STRAIN are mostly determined by the scale factor defined by the software's user (Pesci and Teza, 2007). The default value of the factor is three times greater than the defined mesh grid but any other value may also be entered. This factor is used to modify the weights matrix in the least squares method (Shen et al., 1996). In the mentioned paper, the weighting was implemented in the velocities covariance matrix by the following equation:

$E_{i j}=C_{i j} \cdot \exp \frac{\Delta R_{I}^{2}+\Delta R_{J}^{2}}{\sigma_{D}^{2}}$

where $E_{i j}$ is the covariance matrix for both $\varepsilon_{x}{ }^{I}$ and $\varepsilon_{y}{ }^{I}$ and also the weighted version of $C_{i j}$, simultaneously. $C_{i j}$ is the covariance matrix of the estimated velocities uncertainties, $i$ and $j$ are the components of velocities corresponding to the $I$-th and the $J$-th stations, $\Delta R_{I}$ and $\Delta R_{J}$ are the distances between the considered station ( $I$-th and $J$-th) and the calculated node. $\sigma_{D}$ is the constant value that determines the radius from which the data will have the major influence on the calculated strain node. The results are averaged using this factor, all data points which lie within a defined radius are taken into consideration and thus the strains do not strictly correspond to these determined by the nearest stations only.

\section{DETERMINATION OF THE LOCAL STRAIN FIELD}

Several papers concerning deformations have already been published. Grenerczy et al. (2000) determined the general strain pattern of Central Europe from two subnetworks: the Northern containing the earlier orogenic structures and the Southern in the Alpine collision zone. These determinations were based on the Central European GPS Geodynamic Reference Network (CEGRN) and the Hungarian GPS Geodynamic Reference Network (HGRN) campaigns. Grenerczy (2002) combined the results from several GPS networks in Central Europe operated independently with some IGS and EUREF permanent stations incorporated. The strain calculations showed very small and hardly significant value of $1.1 \pm 0.84$ nanostrain/year in the North and East of the Western Carpathians and $-5.7 \pm 1.6$ nanostrain/year in the North Alpine region. Hefty and Duraciova (2003) presented results of the repeated GPS observations (epoch or permanent) processed into 3D velocity field and then translated into surfaře deformation field under the assumption that the examined territory is a continuous environment (Altiner idea). They obtained compressions prevailing over tensions for Central Europe in the range of 1-5 nanostrain/year.

Three levels of data verification were implemented in this research. First one was the statistical level. As it was published in Bogusz et al. (2012), horizontal velocities of the selected stations located in the vicinity of the Sudeten Mts. are characterized by the standard deviation of tens of $\mathrm{mm} /$ year in the extreme case based on the 3-year determinations.

Second one was the significance level. The GRID STRAIN software computes the value of significance of calculations. It shows the areas in which the results correspond to the real deformation the most. It evaluates the significance using two criteria - angular and radial distribution of stations (points) around the calculated strain node for which the deformations are estimated (Pesci and Teza, 2007). In our research more than 300 EPN and ASGEUPOS stations were taken but the results seem to be significant only for the region of Poland due to dense stations distribution. The default scale factor of $75 \mathrm{~km}$ was used. The map with significance areas is shown in Figure 4 for the area of Central Europe. The turquoise areas indicate high significance of the results; gray areas - moderate significance, while white areas - low significance. The strain factor of about $75 \mathrm{~km}$ determines the local character of the obtained deformations and reflects the kinematics of the described area. For this factor only area of Poland is covered with the areas of high and moderate significance of calculations what is guaranteed by the dense distribution of the ASG-EUPOS stations. The authors state that using the value of strain factor close to the mean distance between the data points should 


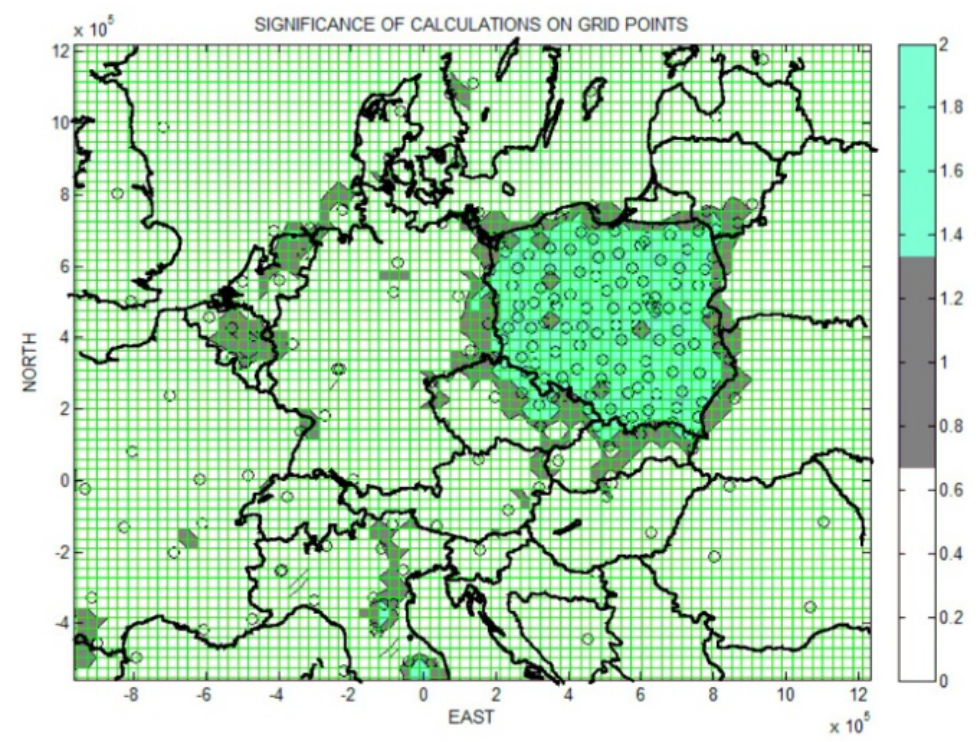

Fig. 4 Significance values for the area of Central Europe.

provide the most local appearance of the strain field. Using too high value of the factor will average the results and therefore will not give us reliable information about strains but will characterize only overall deformations.

Subsequently our model (the factor of about $75 \mathrm{~km})$ still indicated the areas of abnormal strain values (Fig. 5).

Unexpected strain values were noticed and no logical explanation for them was found. Statistically, the stations work correctly. Geologically, in a tectonically stable region as the area of Poland, such unexpected values and directions of tension or compression result only from the fact that the real deformation that can be recorded by the station is smaller than the effect of antennae instability. The authors decided to implement the third level of verification: to generate the strains that would depend only on the nearest velocities in order to find stations outlying from the others.

\section{CALCULATION OF STRAINS IN THE TRIANGLES}

The Delaunay triangulation (Delaunay, 1934) enables to divide, according to strictly defined algorithms, any Euclidean space into triangles formed by a discrete set of points belonging to this space. The mesh of the triangles made by means of the Delaunay triangulation may be used, among others in interpolation, the finite element method or the finite volume method.

Let $V$ be a set of $N$ of at least 3 non-collinear points of Euclidean space. The Delaunay triangulation associates in such a conjunction all of the points into triangles, such that a circle circums $\backslash$ cribed on each of the triangles does not contain any other point (the criterion of the circle). The angles in each of the newly created triangles are maximized - so that each of the triangles is as close to an equilateral one as possible (formation of obtuse triangles is avoided) - the criterion of the angles. We can call it the Delaunay triangulation only if both of the above criteria are fulfilled. With these properties, this triangulation method is often used for generating the Digital Terrain Models (DTM). The Delaunay triangulation for a set of $N$ discrete points corresponds to a division of the plane according to the Voronoi tessellation rules, i.e. such a division of plane including $N$ points into convex polygons in which each of the polygons contains exactly one point that generates it and each of the points included in this polygon is closer to the point that generates it than to the others. In case of the Euclidean space with the set of points $V=\left\{v_{1}, \ldots v_{N}\right\}, N \geq 3$ and the Euclidean distance between the discussed points equal to $d\left(v_{i}, v_{j}\right)$, the Voronoi polygon will then be defined as (Voronoi, 1907):

$V(i)=\left\{x \in E^{2}: d\left(x, v_{i}\right) \leq d\left(x, v_{j}\right), j=1, \ldots, N\right\}$

where $x$ is any point of the newly formed polygon, generated by the vertex from the set $V$. The set of the triangles created by the combination of points generating the two adjacent Voronoi polygons (that are called the Voronoi neighbours), generates the Delaunay triangulation. Therefore, the Voronoi tessellation may be used alternatively to the Delaunay triangulation.

Several algorithms were created to simplify the whole process by checking the above mentioned conditions which triangulation has to fulfil. The following ones can be distinguished:

- the algorit $/ \mathrm{hm}$ of Guibas and Stolfi (1985),

- the algorithm of flipping the side of the triangles (De Berg et al., 2008),

- the incremental algorithm (Guibas et al., 1992; Bowyer, 1981; Watson, 1981; De Berg et al., 2008), 


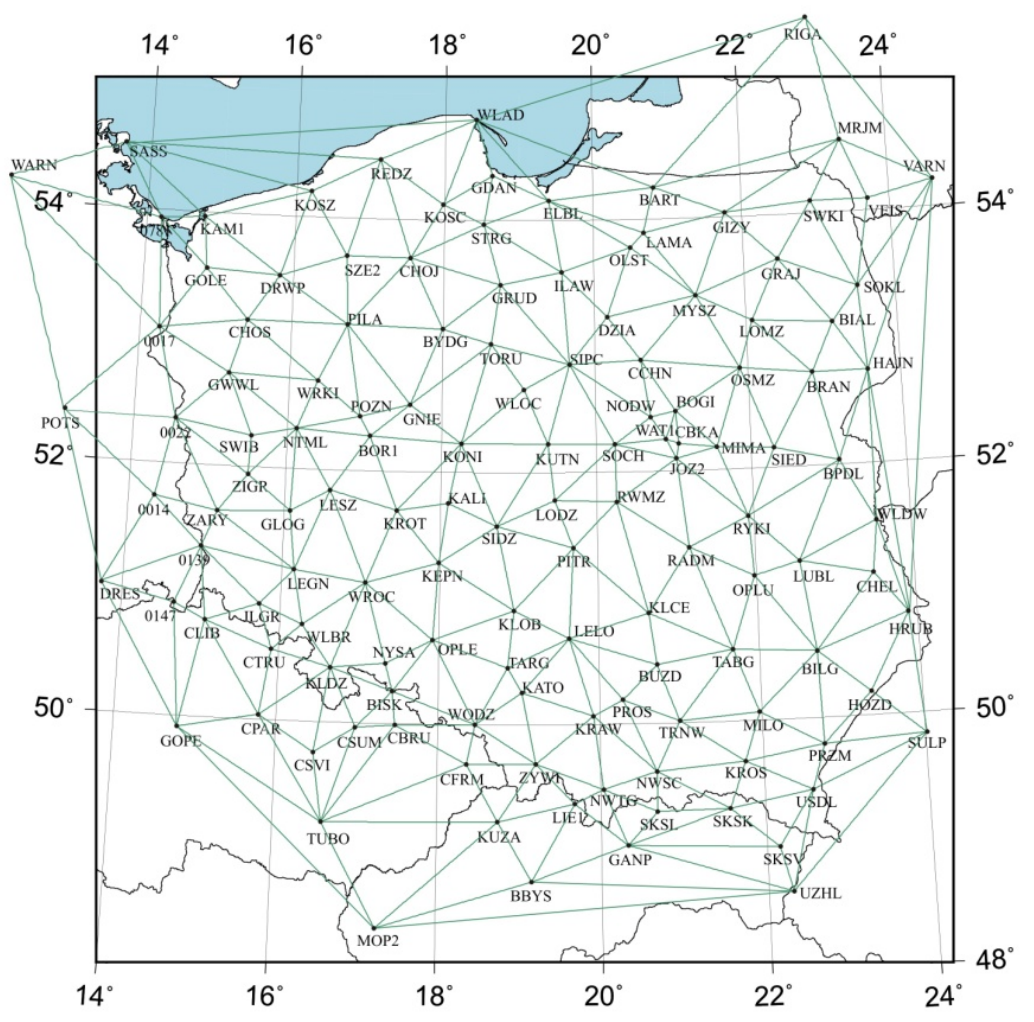

Fig. 6 Triangles formed by means of the Delaunay triangulation based on the EPN and the ASG-EUPOS stations.

- the algorithm of Fortune (Fortune, 1986; Austin, 2012),

- the algorithm of Divide and Conquer (Guibas and Stolfi, 1985; Peterson, 2012),

In this research, the Delaunay triangulation between data points was conducted by using the GMT software (The Generic Mapping Tools; Wessel and Smith, 1998). Figure 6 presents triangles obtained among the ASG-EUPOS stations and the neighbouring ones.

The strains were calculated in the centre of the mass of the triangles formed by the Delaunay triangulation based on the differences between the points velocities. The main components of strain were obtained with the following formula:

$$
\begin{aligned}
V_{i j} & =D \cdot S \Rightarrow\left[\begin{array}{c}
\Delta v_{N_{12}} \\
\Delta v_{E_{12}} \\
\Delta v_{N_{13}} \\
\Delta v_{E_{13}}
\end{array}\right]= \\
& =\left[\begin{array}{cccc}
\Delta \phi_{12} & \Delta \lambda_{12} & 0 & \Delta \lambda_{12} \\
0 & \Delta \phi_{12} & \Delta \lambda_{12} & -\Delta \phi_{12} \\
\Delta \phi_{13} & \Delta \lambda_{13} & 0 & \Delta \lambda_{13} \\
0 & \Delta \phi_{13} & \Delta \lambda_{13} & -\Delta \phi_{13}
\end{array}\right] \cdot\left[\begin{array}{c}
e_{x x} \\
e_{x y} \\
e_{y y} \\
\omega
\end{array}\right]
\end{aligned}
$$

where $S$ is the matrix containing strain parameters, $D$ is the matrix with the differences between stations latitude and longitude respectively, $V_{i j}$ is formed by the differences between stations velocities. One selected vertex in each of the triangles was stated to be the "zero" one. The strains presented in Figure 7 were obtained using the equation 4 for the stations velocities in the ITRF2008 and their uncertainties (estimated with CATREF).

\section{VERIFICATION OF STATIONS VELOCITIES}

Verification of the EPN and the ASG-EUPOS stations was based on the strains values. From previously made researches (Jarosinski et al., 2006; Jarosinski, 2005; 1998) it may be noticed that the strains should not exceed the value of 3-4 nanostrains/year. The higher values may only result from some local effects, the artefacts of the system or they prove that the antennae stabilization is inadequate for the geodynamical interpretation. The first verification of the strains made us to eliminate 15 stations marked in Figure 8 with red squares. The selection was determined by the fact that the strains calculated for each triangle with the same vertex exceeded 5 nanostrain/year value. After removal of the stations, new triangles were formed and the strains were recalculated.

After first verification of stations and recalculation of strains, a few of their values were still recognized to stand out from the assumed ones. 


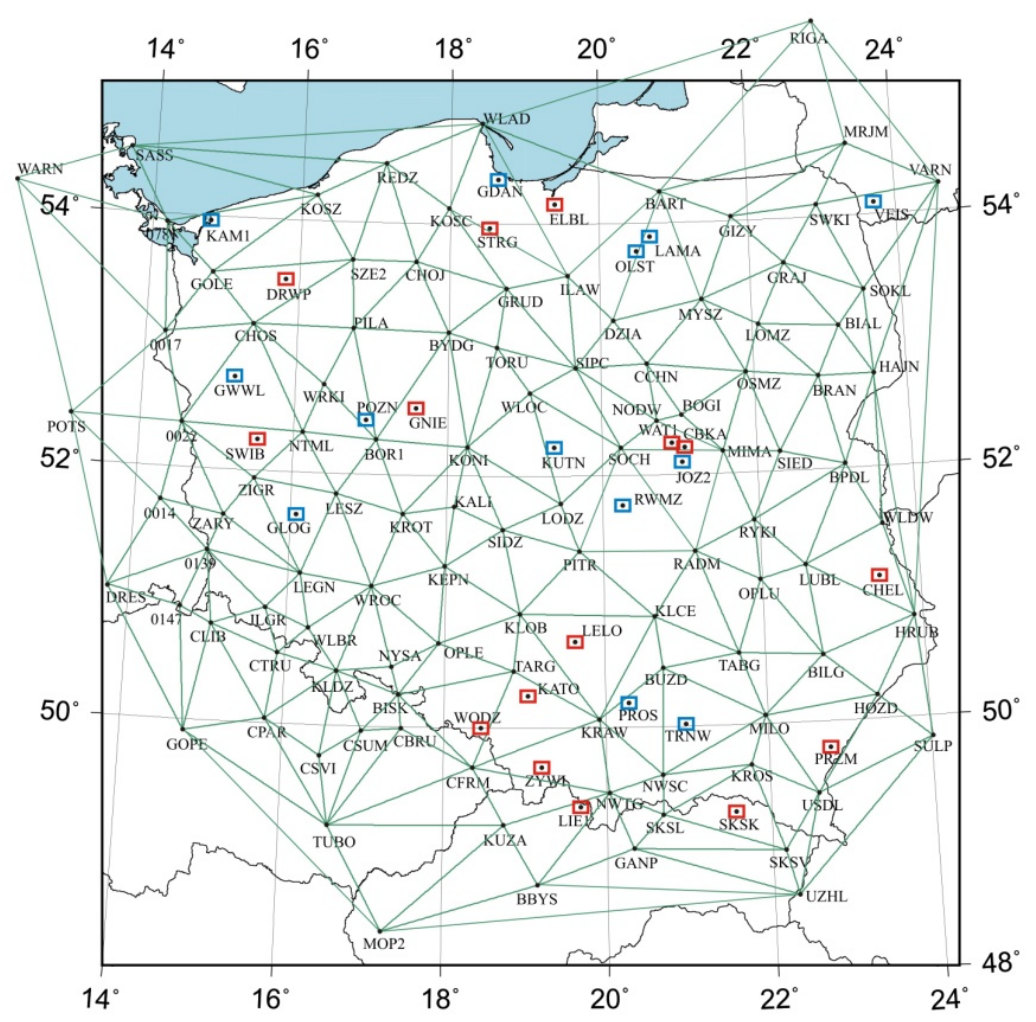

Fig. 9 All of the excluded stations and the final triangles.

Except for the area of the Sudeten and the Carpathians (the Southern part of Poland), where the strains can be characterised by uncorrelated directions and values (it depends on which of the mountains slopes they are placed on), the area of Poland is a tectonically stable region. For this reason, the second data verification was needed. Thirteen more sites were excluded (Fig. 9, blue squares). In the next step, the formula of strains estimation was repeated. Figure 10 shows the final strains in the triangles made by means of the Delaunay triangulation. The larger (than in the previous figures) scale of strains was implemented.

Figure 11 presents the results of the continuous strain field (no geological background was implemented) for the area of Poland which was obtained by GRID_STRAIN software after final data verification with the strain factor of about $75 \mathrm{~km}$.

\section{DISCUSSION OF THE RESULTS}

Multilateral analysis of the deformation field executed for the EPN and the ASG-EUPOS network stations was aimed to check usefulness of the networks for research concerning current geodynamics of the lithosphere. Since the stations of the networks do not have the required stabilization for such a research, it is necessary to be aware that disturbances of tectonic deformations may occur due to technological dislocations. Initial computations of deformations executed for all network stations proved great differentiation indicating insufficient stabi- lization of numerous stations of the network. Elimination of unstable stations was conducted in subsequent steps of data filtration. The final results of deformations computation were assessed with respect to mutual consistency for greater domains as well as their compatibility with the current status of tension and state of knowledge of geodynamics and tectonic structure of the investigated area.

Generally, the determined continuous strain field for the area of Poland is in a good agreement with the recent geological knowledge. For the assumed parameters of interpolation and the smoothing function, we obtained a relatively uniform image of deformation for the whole area of Poland. Compression in the direction of NNE-SSW is at a constant rate of about 2 to 5 nanostrain/year, except for the area of Podlaskie and Lubelskie where the compression rate is below 1 nanostrain/year. This direction is compatible with the drift of the Eurasian plate which suggests that the obtained compression direction is reliable. At the current state of knowledge, it is hard to explain the increase of the deformation rate in the North-Eastern part of the country for which, despite the coldest and the most rigid lithosphere, the largest rate of compression was obtained. On the other hand, the largest rate of tension, exceeding compression, was computed for the North-Western part of Poland. Although such regime of deformation is also observed in a significant part of East European Craton, it may be suspected that it is 


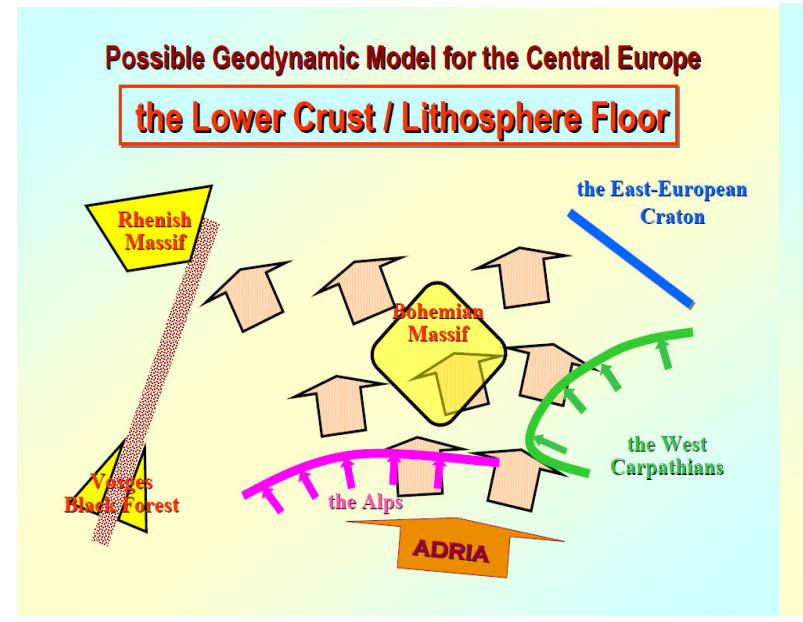

Possible Geodynamic Model for the Central Europe the Upper Crust Floor

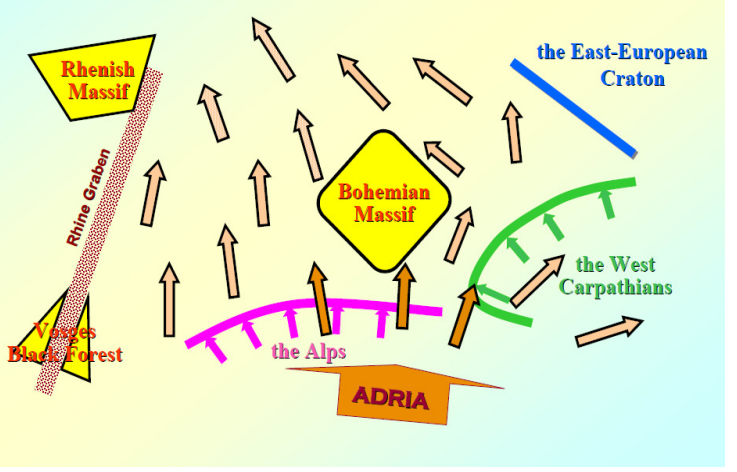

Fig. 13 The geodynamic model of Central Europe (Schenk et al., 2007).

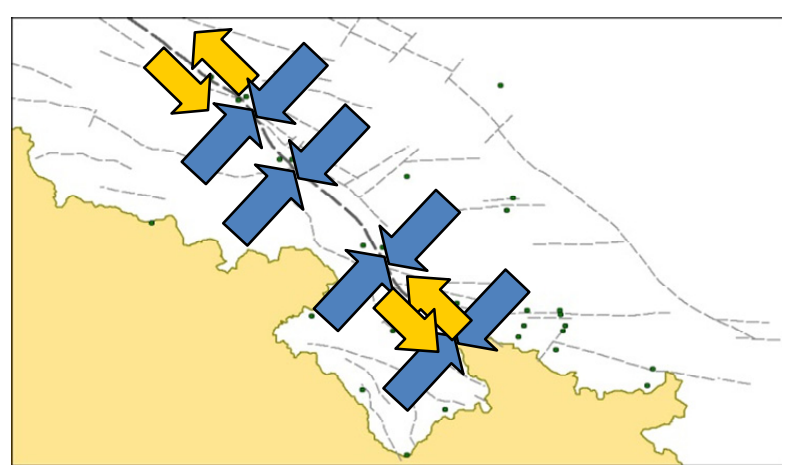

Fig. 14 Deformations of the Sudetic Marginal Fault Zone - Hypothetical Model (Kontny, 2003).

caused by algorithms smoothing the computation results. Tension beyond craton might result from shifting movement along Teisseyre-Tornquist Zone. The obtained image does not reflect local variability of the deformation field related to active dislocation zones. In the solution for the triangles the deformation is locally significantly differentiated; other directions of compression are also prevailing (N-S and NNWSSE, Fig. 10) unlike in the solution for the regular grid in which the NNE-SSW compression direction dominates (Fig. 11). The directions of compression for Poland show a relative consistency and a relation with respect to the directions of tensions which may be explained by geodynamic factors. The deformation rates computed for the triangles are more varied what indicates a possible contribution of disturbances resulting from instabilities of the measurement stations. The smoothed image of deformation for the regular grid of interpolation points indicates that compression in the direction of the drift of the Eurasian plate (NNE-SSW) prevails in general on the area of Poland. This direction is in a good agreement with dominating directions of compression determined for the triangles (Fig. 10). It proves that the data verification is necessary before estimating the deformations. If we consider unreliable velocities, we can obtain distorted results that should not be interpreted as geological changes because they appeared only as an unexpected effect of the unreliable stations. What is more, the obtained strain field was in a good agreement with the WSM database (World Stress Map - www.world-stress-map.org).

\section{LOCAL STRAIN FIELD}

The Sudeten area proved the existence of the typoval direction of compression prolonged from the Africa push as well. During the Alpine orogeny, the Sudeten were divided into several tectonic blocks which were selectively uplifted. In spite of numeric volcanic eruptions in the Tertiary, nowadays the Sudeten are characterized by relative tectonic stability. The horizontal deformations estimated and then visualized on the map are consistent with the strains obtained from the long geological researches (Fig. 12).

The main directions of deformations determined in this research, especially directions of the maximum compressions of the Sudeten area match the earlier published models: the model of the Recent Crustal Stress Field in Central Europe developed by Gruntal and Stromeyer (1992); the geodynamic model of Central Europe (Lower and Upper Crust) developed by Schenk et al. (2007) (Fig. 13); the hypothetical model of deformations of the Sudetic Marginal Fault Zone derived by Kontny (2003) from yearly repeated GPS epoch measurements (Fig. 14) and the model of the stress regime in the Northern foreland of the Carpathians developed by Jarosinski et al. (2009).

The model of local deformations presented in Figure 12 is smoothed what result both from the fact of non-considering the tectonic discontinuity of area (faults) and also from the properties of the method of the interpolation. Much considerable values of the velocities of main deformations (both compressions 
and tensions) in NW part of analysed area in comparison to adjacent areas are difficult to interpret in terms of cause-and-effect. Values of deformations below and above the Mid-Odra River Fault Zone differ much from each other, strains in the Bohemian Massif (treated with the Sudeten mountains) are smaller than for Fore-Sudetic Monocline, especially a tension component NW-SE in Sudeten part is much smaller than for Monocline. This effect can be triggered with influence of pushing the Alps on relatively stiff area of the Bohemian Massif, so only on the area of For-Sudetic Monocline crosswise tension towards main direction of compression structures is appearing. This interpretation is consistent with the assumptions of the model proposed by Schenk et al. (2007).

The density of the analyzed networks in Sudeten area is still not sufficient for investigating local and very complicated geological structures. New stations have to be incorporated into the research. The authors of the GRID_STRAIN software provided also its 3D version which gives the results in the nodes of the Digital Terrain Model of the area for which the strains are estimated. In near future, this modelling will also be supplemented by models of vertical movements obtained from precise levelling (Kowalczyk, 2005; 2008 , Kowalczyk et al. 2010; 2011) in order to obtain the most reliable field of deformation.

\section{ACKNOWLEDGMENTS}

This research is supported by the Polish Ministry of Science and Higher Education, grants No. 0960/R/T02/2010/10 and 2314/B/T02/2010/39.

\section{REFERENCES}

Altamimi, Z., Sillard, P. and Boucher, C.: 2007, CATREF software: Combination and analysis of terrestrial reference frames. LAREG Technical, Institut Géographique National, Paris, France.

Altamimi, Z., Collilieux, X. and Métivier, L.: 2011, ITRF2008: an improved solution of the international terrestrial reference frame. J Geod., 85, 457-473. DOI: $10.1007 / \mathrm{s} 00190-011-0444-4$.

Austin, D. (as on 2012-10-29): Voronoi Diagrams and a Day at the Beach. Feature Column. Monthly essays on mathematical topics.

http://www.ams.org/samplings/feature-column/fcarcvoronoi.

Bogusz J. and Figurski M.: 2012, GPS-derived height changes in diurnal and sub-diurnal timescales. Acta Geophysica, 60, no. 2, 295-317. DOI: 10.2478/s11600-011-0074-5.

Bogusz, J., Figurski, M., Kontny, B. and Grzempowski, P.: 2012, Horizontal velocity field derived from EPN and ASG-EUPOS satellite data on the example of southwestern part of Poland. Acta Geodyn. Geomater., 9, No. 3 (167), 349-357.

Bogusz, J., Kłos, A., Grzempowski, P. and Kontny, B.: 2013, Modelling the velocity field in a regular grid in the area of Poland on the basis of the velocities of European permanent stations. Pure and Applied Geophysics. DOI: 10.1007/s00024-013-0645-2
Borkowski, A., Bosy, J. and Kontny, B.: 2003, Time series analysis of EPN stations as a criterion of choice of reference stations for local geodynamic networks. Artificial Satellites - Journal of Planetary Geodesy, 38, No. 1, 15-27.

Boucher, C. and Altamimi, Z.: 2011, Memo: Specifications for reference frame fixing in the analysis of a EUREF GPS campaign (v.8), (http://etrs89.ensg.ign.fr/memoV8.pdf.

Bowyer, A.: 1981, Computing Dirichlet tessellations. The Computer Journal 24 (2), 162-166.

De Berg, M., Cheong, O., van Kreveld, M. and Overmars, M.: 2008, Computational Geometry: Algorithms and Applications. Springer-Verlag. 191-218.

Delaunay, B.: 1934, Sur la sphere vide, Izvestia Akademii Nauk SSSR, Otdelenie Matematicheskikh i Estestvennykh Nauk 7, 793-800.

Dong, D., Fang, P., Bock, Y., Cheng, M. K. and Miyazaki, S.: 2002, Anatomy of apparent seasonal variations from GPS-derived site position time series. J. Geophys. Res. 107(B4), 2075. DOI: 10.1029/2001JB000573

England, P. and Molnar, P.: 1997, Active deformation of Asia: From kinematics to dynamics. Science, 278, no. 5338, 647-650. DOI: 10.1126/science.278.5338.647.

England, P. and Molnar, P.: 2005, Late Quaternary to decadal velocity fields in Asia. Journal of Geophysical Research, 110, B12401. DOI: $10.1029 / 2004 J B 003541$

Figurski, M., Szafranek, K., Bogusz, J. and Kamiński, P.: 2010, Investigation on stability of mountainous EUPOS sites' coordinates. Acta Geodyn. Geomater., 7, No. 3 (159), 263-274.

Fortune, S.: 1986, A sweepline algorithm for Voronoi diagrams. Proceedings of the second annual symposium on Computational geometry. Yorktown Heights, New York, United States, 313-322.

Grenerczy, G.: 2002, Towards a dense intraplate velocity map for a Central Europe. Reports on Geodesy No. 1 (61), 27-36.

Grenerczy, G., Kenyeres, A. and Fejes, I.: 2000, Present crustal movements and strain distribution in Central Europe inferred from GPS measurements. J. Geophys. Res., 105(B9), 21835-21847. DOI: $10.1029 / 2000 J B 900127$

Gruenthal, G. and Stromeyer, D.: 1992, The recent crustal stress field in Central Europe - Trajectories and finiteelement modeling. Journal of Geophysical Research, 97, B8, 11.805-11.820. DOI: 10.1029/91JB01963

Guibas, L., Knuth, D. and Sharir, M.: 1992, Randomized incremental construction of Delaunay and Voronoi diagrams. Algorithmica 7, 381-413.

DOI: $10.1007 / \mathrm{BF} 01758770$

Guibas, L. and Stolfi, J.: 1985, Primitives for the manipulation of general subdivisions and the computation of Voronoi. ACM Transactions on Graphics, 4, No. 2, 74-123.

Hefty, J. and Duraciova, R.: 2003, Stochastic properties of deformation characteristic obtained from GPS site velocities. Reports on Geodesy, No.1 (64), 33-40.

Jarosinski, M.: 1998, Contemporary stress field distortion in the Polish part of the Western Outer Carpathians and their basement. Tectonophysics 297, 91-119. DOI: 10.1016/S0040-1951(98)00165-6 
Jarosinski, M.: 2005, Ongoing tectonic reactivation of the Outer Carpathians and its impact on the foreland: Results of borehole breakout measurements in Poland. Tectonophysics $410,189-216$. DOI: $10.1016 /$ j.tecto.2004.12.040

Jarosinski, M., Beekman, F., Bada, G. and Cloetingh, S.: 2006, Redistribution of recent collision push and ridge push in Central Europe: insights from FEM modelling. Geophysical Journal International, 167, 860-880. DOI: 10.1111/j.1365-246X.2006.02979.x

Jarosinski, M., Poprawa, P. and Ziegler, P.: 2009, Cenozoic dynamic evolution of the Polish Platform, Geological Quarterly, 53 (1), 3-26.

Kontny, B.: 2003, Geodetic research of contemporary kinematics of the main tectonic structures of the Polish Sudeten and the Fore-Sudetic Block with the use of GPS measurements (in Polish with English summary). Zeszyty Naukowe AR we Wrocławiu, 468, Rozprawy, CCII, 146.

Kontny, B. and Bogusz, J.: 2012, Models of vertical movements of the Earth crust surface in the area of Poland derived from leveling and GNSS data. Acta Geodyn. Geomater., 9, No. 3 (167), 331-337.

Kowalczyk, K.: 2005, Determination of land uplift in the area of Poland, 6th International Conference Environment, al Engineering, 1 and 2, 903-907.

Kowalczyk, K: 2008, Vertical crustal movements in Poland for instance any fragment three levellings network, 7th International Conference „Environmental Engineering", 3, 1354-1358.

Kowalczyk, K., Rapiński, J. and Mróz, M.: 2010, Analysis of vertical movements modelling through various interpolation techniques, Geodyn. Geomater., 7, No. 4 (160), 399-409.

Kowalczyk, K., Bednarczyk, M. and Kowalczyk, A.: 2011, Relational database of four precise levelling campaigns in Poland, 8th International Conference „Environmental Engineering”, 03/01, 1356-1361.

Lukhnev, A.V., San'kov, V.A., Miroshnichenko, A.I., Ashurkov, S.V. and Calais, E.: 2010, GPS rotation and strain rates in the Baikal-Mongolia region. Russian Geology and Geophysics 51, 785-793.

Pesci, A. and Teza, G.: 2007, Strain rate analysis over the central Apennines from GPS velocities: the development of a new free software. Bollettino di Geodesia e Scienze Affini, 56, 69-88.

Peterson, S. (as at 2012-10-30): Computing constrained Delaunay triangulations. http://www.geom.uiuc.edu/ samuelp/del_project.html

Schenk, V., Cacoń, S., Bosy, J., Kontny, B., Kottnauer, P. and Schenkova, Z.: 2000, GPS network "Sudeten”preliminary results of the campaigns 1998-1999. Reports on Geodesy 7 (53), 25-33.

Schenk, V., Schenkova, Z., Bosy, J. and Kontny, B.: 2010, Reliability of GPS data for geodynamic studies case study: Sudeten area, the Bohemian Massif. Acta Geodyn. Geomater., 7, No. 1 (157), 113-128.
Schenk, V., Schenkova, Z. and Jechumtalova, Z.: 2009, Geodynamic pattern of the West Bohemia region based on permanent GPS movements. Studia Geophysica et Geodetica, 53, No. 3, 329-341. DOI: 10.1007/s1 1200-009-0021-y

Schenk, V., Schenkova, Z., Mantlik, F. and Gracova, M.: 2007, Preliminary Geodynamical Pattern of the Bohemian Massif, 8th Czech-Polish Workshop „On recent geodynamics of the Sudeten and adjacent areas", Kłodzko (Poland), March 29-31.

Schenkova, Z., Kottnauer, P., Schenk, V., Cajthamlova, M., Mantlik, F. and Kujal, R.: 2009, Investigations of the recent crustal movements of the Eastern part of the Bohemian Massif using GPS technology. Acta Research Reports. No. 18, 17-25.

Schenkova, Z., Schenk, V., Mantlik, F. and Gracova, M.: 2007, Regional Geodynamic Network Highlands, the Bohemian Massif. Acta Geodyn. Geomater., 4, No. 4 (148), 207-215.

Shagimuratov, I.I., Baran, L.W., Wielgosz, P. and Yakimova, G.A.: 2002, The structure of mid- and high-latitude ionosphere during September 1999 storm event obtained from GPS observations, Annales Geophysicae, 20, No 5, 665-660.

Shen, Z.-K., Jackson, D.D. and Ge, B.X.: 1996, Crustal deformation across and beyond the Los Angeles basin from geodetic measurements. Journal of Geophysical Research, 101, 27957-27980.

DOI: 10.1029/96JB02544

Teza, G., Pesci, A. and Galgaro, A.: 2008, Grid strain and grid_strain3: Software packages for strain field computation in 2D and 3D environments. Computers \& Geosciences 34(9), 1142-1153.

Voronoi, G.: 1907, Nouvelles applications des paramètres continus à la théorie des formes quadratiques. J. reine angew. Math. 133, 97-178.

Watson, D.F.: 1981, Computing the n-dimensional Delaunay tessellation with application to Voronoi polytopes. The Computer Journal 24 (2), 167-172.

Wessel, P. and Smith, W.H.F.: 1998, New, improved version of the Generic Mapping Tools. Released, EOS Trans. AGU, 79, 579. 


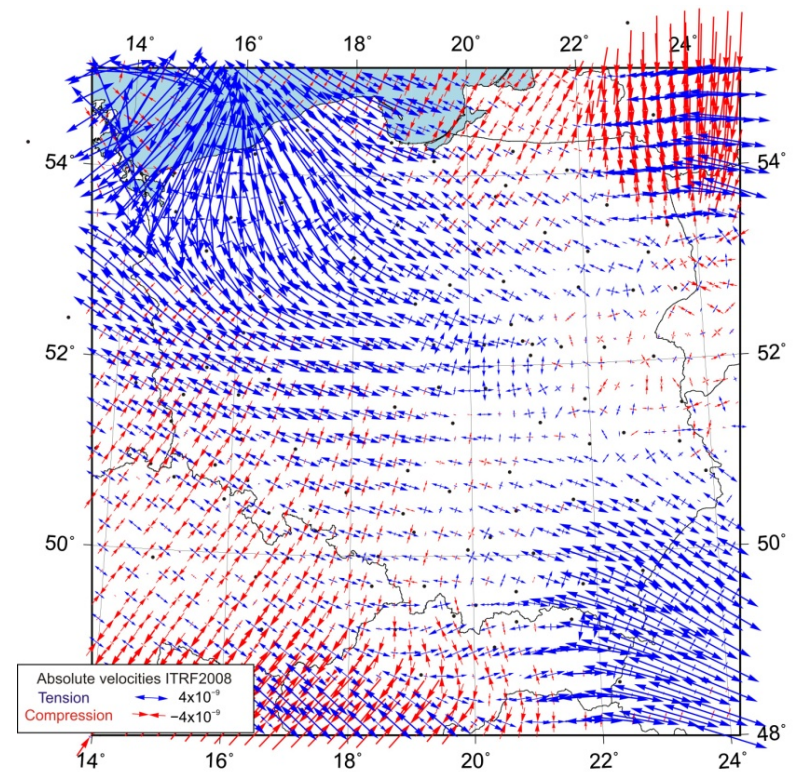

Fig. 5 Strain field obtained without data verification.

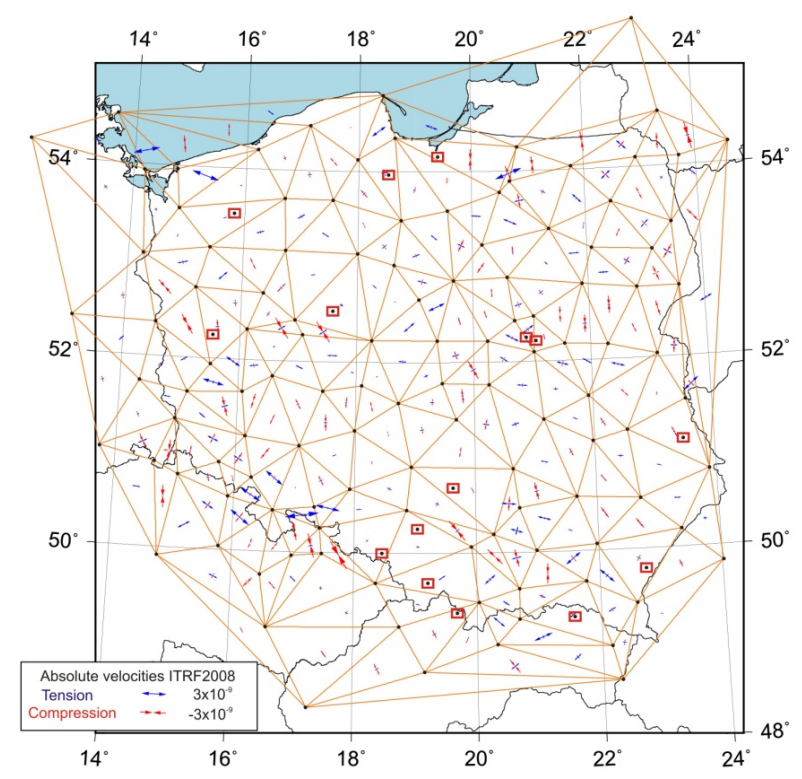

Fig. 8 The first verification of stations with the newly formed triangles.

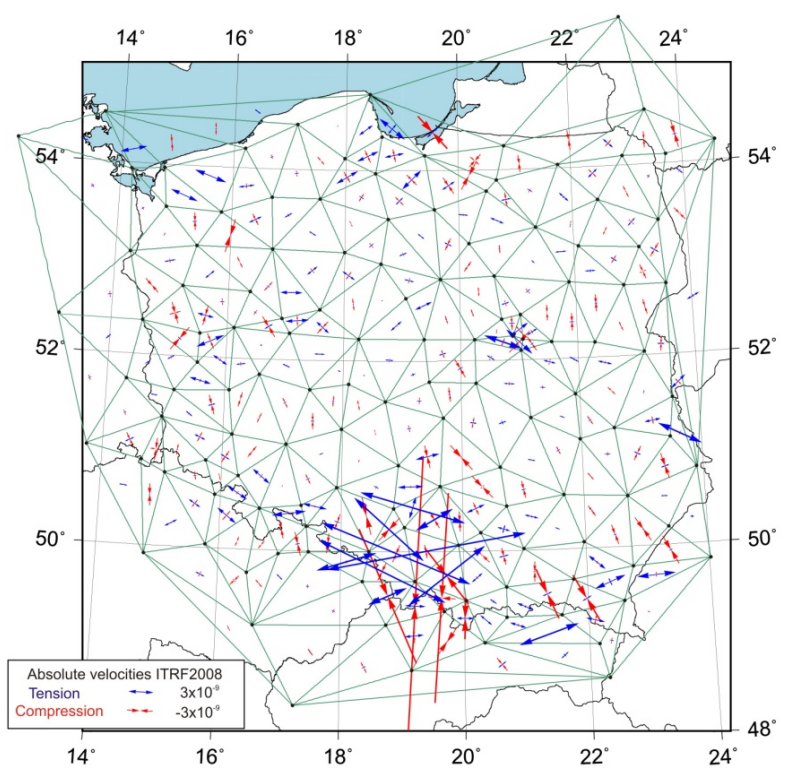

Fig. 7 Strains in the triangles - first approximation.

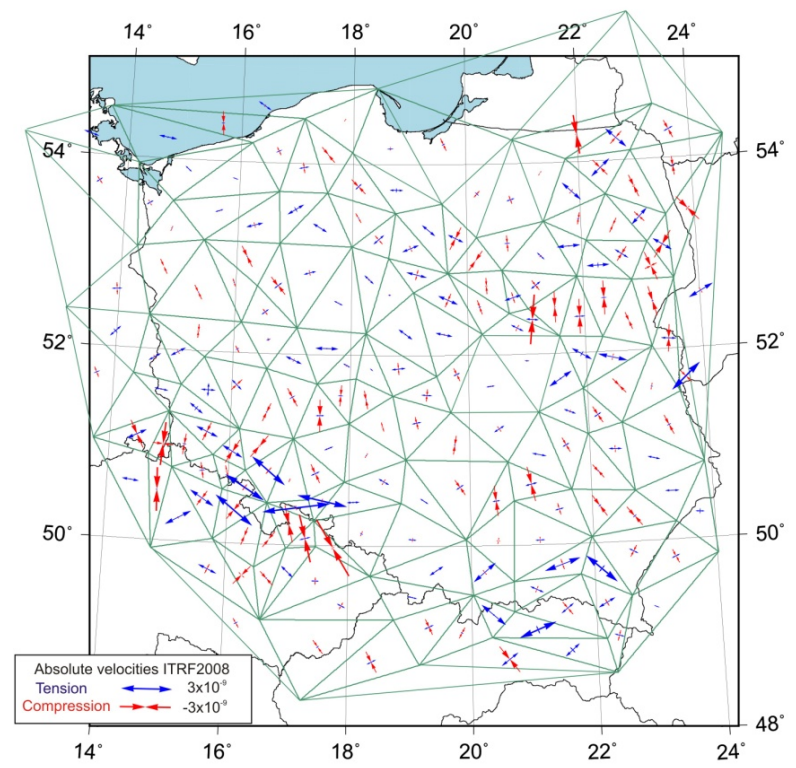

Fig. 10 Strains obtained after the final stations' verification. 


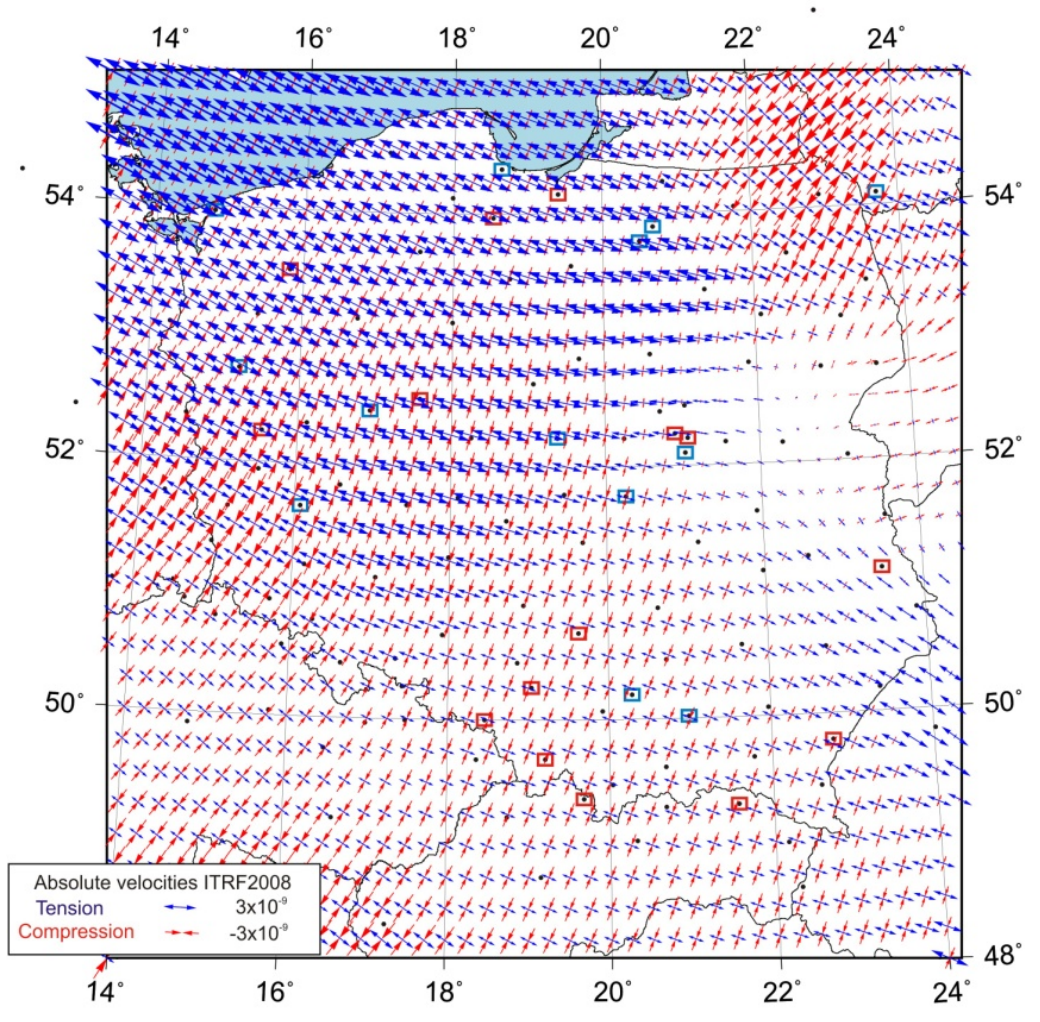

Fig. 11 Continuous strain field after the final data verification (the excluded stations are also marked to show what influence they had on the appearance of the strain field).

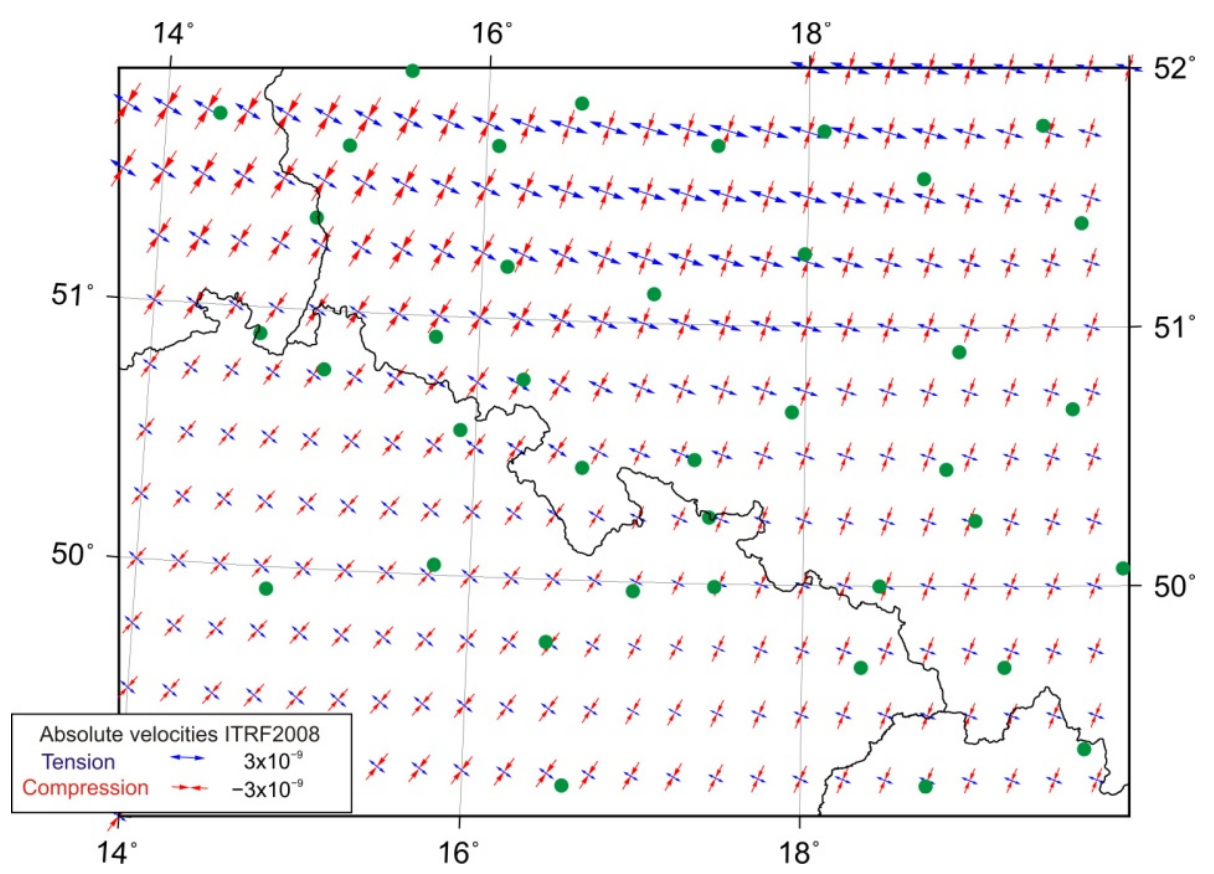

Fig. 12 Strains for the Sudeten area. 